\title{
Editorial
}

\section{International Polar Year}

$\mathrm{T}$ he International Polar Year (IPY) began at a formal international opening ceremony in Paris on 1 March 2007. With a Secretariat in place, over 40 countries signed up to participate and an estimate from David Carlson, the Executive Director, that the activities will involve around 50,000 people over the two years, all seems set for a major leap forward. The coverage is uneven, both geographically and scientifically, and, in many cases, the funding is largely from existing allocations with programmes being re-badged to fit the IPY objectives. But there are some countries who have seized this opportunity to provide significant new funds for new programmes. And there is an enthusiastic core of scientists around the world who see this as a real opportunity.

Looking back fifty years it is clear that the International Geophysical Year (IGY) was of enormous importance scientifically, politically and to a great many of the general public. Can this anniversary event have a similar legacy? The world has changed enormously since 1957 and neither the science nor the politics work in the same way. Then, with the Cold War between USSR and the USA, more limited public communications, a feeling in the science community that they could do something original through international collaboration, and post-war enthusiasm for something new, the scene was set for both political and public engagement. What is lacking this time is the same overt political enthusiasm and public interest that could make this a milestone like IGY.

David Carson, in describing the IPY, suggested that it could be as exciting and important as reaching the Moon. Looking through the list of projects I cannot see why that should be so. This time there are no really exciting iconic activities - like the first satellite "Sputnik" and the first crossing of the continent by the Trans-Antarctic Expedition - to catch the public eye and force political attention. There is no Cold War to heighten the tension between the major Powers and goad them into spending money like water on infrastructure. And the public in the 21st century are so overwhelmed with information that it will be hard to make IPY stand out. It certainly is not because the questions being addressed are not interesting and important but more that the competition for public interest is now more fierce and, for many people, the polar regions are too far away to be of any consequence. To counter this there is a much more sophisticated attempt to use all aspects of the modern media to engage with the public, and to link the activities with education to enthuse the next generation. IPY will also build on the public interest in the existing polar programmes concerned with global change.

So what can we realistically expect from the IPY as its legacy? There are lots of carefully chosen words in the IPY document about "improved understanding" and "increased leverage", about "multidisciplinarity" and "cultural diversity". Some will find new opportunities and ideas from their collaborations, and there is always the possibility of an unexpected break through in a crucial field that will change the way we predict the future. There could indeed be a commitment to fund new long term monitoring sites and successful attempts at multidisciplinary approaches to complex problems. For me the most important legacy would be that the polar regions are seen as a seamless yet critical part of the global picture, that their science will more closely influence international policy and that their conservation and good management will be seen as a political priority by all the countries involved. These may be much less tangible outcomes than the objectives on the IPY web site but they could be of greater long-term importance.

DAVID W.H. WALTON 
https://doi.org/10.1017/S0954102007000016 Published online by Cambridge University Press 